\title{
Modeling capital structure decisions in a transition market: empirical analysis of firms in Egypt
}

\author{
Tarek I. Eldomiaty $\cdot$ Mohamed A. Ismail
}

Published online: 2 May 2008

(C) The Author(s) 2008

\begin{abstract}
It has been realized that none of the three basic theories of capital structure presents a complete answer to the actual determinants of corporate financing decisions. This study attempts to model the practice of capital structure decisions according to the basic premises of each theory of capital structure: trade-off theory, pecking-order theory and free cash flow theory. The methodology addresses modeling long-term and short-term debt financing decisions based on ten different statistical criteria using data from Egypt stock market. The empirical evidence indicates that four models of corporate financing are influenced by the trade-off theory relatively. The contributions of this paper are as follows. First, this study offers a more refined and comprehensive methodology for modeling firms' capital structure decisions. Second, the results of this study compare to those of previous studies of other developing countries and thus add an element of external validity.
\end{abstract}

Keywords Capital structure $\cdot$ Modeling $\cdot$ Subset selection $\cdot$ Egypt

JEL Classification G32

\section{Introduction}

The literature on the theory and practice of capital structure is extensive. Researchers have attempted to provide answers to such questions as what are the factors that affect firm's

Mohamed A. Ismail is currently working as a consultant for the Information and Decision Support Center (IDSC), the Egyptian Cabinet-Egypt. He would like to acknowledge the financial support provided by the IDSC.

T. I. Eldomiaty $(\bowtie)$

College of Business Administration, University of Dubai, PO Box 14143, Dubai, UAE

e-mail: tdomiaty@ud.ac.ae; tarek_eldomiaty@hotmail.com

M. A. Ismail

Faculty of Economics and Political Sciences, Statistics Department, Cairo University, Giza, Egypt

e-mail: m.ismail@idsc.net.eg 
decision to change its capital structure (e.g., leverage or debt ratio). The research on the determinants of capital structure has provided a wide range of factors that combine the effects of trade-off theory, pecking order theory and free cash flow theory (Chen and Kim 1979; Myers 2001; Sánchez-Vidal and Martin-Ugedo 2005). This research has been oriented to determine the factors that matter (or do not matter) in explaining variations in firms' capital structure (Miller 1988). The empirical research on tests of theories of capital structure follows standard, and mostly conventional, estimation procedures to examine the critical determinants of capital structure according to the premises of a certain theory. These procedures rely on the standard statistical runs that depend on conventional criteria for choosing certain model(s). To that end, this study extends the statistical procedures by employing comprehensive statistical criteria to choose the model that best reflects the practice of debt financing.

In reality, it is hard to assume that corporate financing decisions are made according to the precise assumptions of a certain capital structure theory. Rather, it is more tolerable to assume that corporate financing decisions are affected by many different factors (internal and external) that require further investigation. Myers (2001) states that the three theories of capital structure are 'conditional' in a sense that each works out under its own assumptions and propositions. Therefore, none of the three theories can give a complete picture of the practice of the determinants of corporate financing (capital structure) decisions. That is, in practice, it is expected that when the business conditions change, the financing decisions and strategies may change, moving from one theory to another. For example, in certain times, the tax rate may be high enough to encourage more debt financing to take advantage of tax savings or tax shields (trade-off theory). When some economic factors change and the tax shields are not that encouraging, the firm may seek financing from internal sources (pecking order theory) until the tax conditions favor more borrowing. Moreover, a firm may deliberately consume the free cash flow (when it heavily depends on internal sources of financing to finance investment projects) to prevent the agency problems from arising. In sum, it is easily observable that two or more theories of capital structure may exist and affect corporate financing strategies at the same time. This requires more investigation of the factors or determinants that actually affect corporate financing decisions. This paper examines number of determinants of capital structure that have been considered proxies for each of the three theories of capital structure.

\subsection{Why modeling capital structure in transition market?}

The search for the most reliable and relevant determinants of capital structure in a transition market is particularly significant for certain reasons. First, compared with developed markets, the stock markets in transitional countries are relatively less efficient which raises the importance of searching for the most reliable factors that determine the practice of capital structure decisions. Second, information asymmetry in transitional markets is relatively higher than that of developed markets. This means that the capital structure decisions may not be foreseen. This requires an examination of the financial factors that help lessen the degree of asymmetry. Third, in a stage of transition, the countries' capital markets are quite influenced by global forces mostly from developed markets. This raises the question of the extent to which the determinants of capital structure that have evolved in developed markets have an influence generally in a 
transition market and particularly in Egypt. According to the three reasons mentioned above, the paper tests the hypothesis that:

Due to transitional markets less efficiency, information asymmetry and global convergence, capital structure decisions in transition markets are relatively influenced by the three theories of capital structure.

The methodology of this paper utilizes a model selection approach to determine the most common factors that are associated with firm's capital structure decision. The basic objective of the paper is to choose a group of factors (or determinants) that affects firms' debt financing decisions the most. This group can be viewed as a model that describes the practice of firm's financing decisions. This process is to do with modeling firms' capital structure decisions. In regression analysis, modeling depends on selecting a group (or subset) of factors according to number of statistical criteria. That is, in regression analysis, the subset selection of predictors that should be used is an important problem when building a regression model. In general, the reasons for subset selection include (1) identifying important and negligible predictors; (2) modeling the relationship between the dependent variable and the predictors as simply as possible; (3) minimizing cost of prediction. Several subset selection criteria have been proposed in the statistics literature. These criteria select the subset that minimizes a quantity usually expressed as the logarithm maximum likelihood residual sum of squares plus a penalty function which depends on the subset size. Different penalty functions result in different criteria. The most popular criteria are Akaike's Information Criterion AIC (Akaike 1973), Bayes Information Criterion BIC (Schwarz 1978) and $C_{p}$ (Mallows 1973). For a good survey see Hocking (1976), Draper and Smith (1981) and Miller (1990) among others. In this study we employ ten subsets selection criteria (which are discussed in Sect. 5) to identify the most common determinants that are highly associated with firm's capital structure decisions.

The contribution of this paper can be outlined in two elements: (a) it is the first attempt to employ subset selection criteria for capital structure modeling in a transition market, (b) In this study, the authors employ ten subsets selection criteria, while recently, using data from a developed market, Frank and Goyal (2004) present a study of choosing the most reliable determinants of capital structure. They used only one criterion, which is the Bayesian Information Criterion (BIC), for the purpose of subset selection. It is worth to note that the ten criteria we employ in the present study offer a relatively high refined modeling process. It is worth to note that the authors focus in the literature review on the determinants of capital structure in developed markets mostly the U.S. This has significant implications to transition markets. That is, since in general the financial institutions and infrastructure in transition markets vary from those of the developed markets, it offers an opportunity for the financial managers in transition markets, particularly Egypt, to learn lesson from developed markets regarding the determinants of capital structure that are to be considered 'relevant' to transitional market settings.

The rest of the paper is organized as follows. Section 2 reviews the relevant literature on the determinants of capital structure. Section 3 describes the research variables and the proxies. Section 4 describes the data used and the methodology employed for the modeling purpose. Section 5 discusses the ten subsets selection criteria used for the modeling process. Section 6 shows the results. Section 7 discusses the results. Section 8 concludes. 


\section{Determinants of capital structure: review of the relevant literature}

The relevant literature on the determinants of capital structure provides number of factors that have been examined or even pointed out. It has been realized that the number of factors differs from one study to another. Therefore, this study examines as a comprehensive number of determinants of capital structure as possible. These determinants cover relatively the tradeoff theory, pecking order theory and free cash flow theory. Some determinants could not be included due to the lack of relevant data. Table 1 summarizes the capital structure determinants examined in this study and the ratio(s) or proxy for each determinant.

\section{Variables and research proxies}

\subsection{Dependent variables}

The initial two dependent variables examined in this study are firms' changes in long-term debt ratio $(\triangle L T D R)$ and changes in short-term debt ratio $(\triangle S T D R)$. The measurement of the two variables is to address firms' adjustment to a target value. Therefore, the change in long-term debt ratio is denoted to as $Y_{1 t}=\Delta L T D R_{t}=L T D R_{t}-L T D R_{t-1}$ and the change in short-term debt ratio is denoted to as $Y_{2 t}=\Delta S T D R_{t}=S T D R_{t}-S T D R_{t-1}$.

Nevertheless, the practice of corporate debt financing might not seem as simple as its classification into long-term and short-term components. Two potential problems may arise. First, a potential substantial problem arises in that the changes in these two variables are not independent. In particular, a given firm might have short-term debt outstanding in year-end $t$ which is due in year $t+1$. In year $t+1$, the firm might borrow long-term debt in part to pay-off maturing short-term debt. In this case, the change in short-term debt (a decrease) occurs simply because the short-term debt matures, while the simultaneous change in the long-term debt (i.e., an increase) occurs simply because the proceeds are needed to pay-off the maturing short-term debt. It is worth noting that a great part of the debt financing pattern in Egypt is a good example of the above mentioned scenario. To deal with this possibility, the authors experiment with a third alternative dependent variable which is the change in all debt (denoted to as $\left.Y_{3 t}=\Delta \mathrm{DR}=\mathrm{DR}_{t}-\mathrm{DR}_{t-1}\right)$.

Second, the use of short-term debt may create another potential problem. Myers (1977) and Graham (1996) argue that firms may limit total debt, or use short-term debt, to minimize underinvestment costs. This theory necessitates the examination of the effect of short-term debt independently which is measured by a fourth dependent variable $Y_{4 t}=$ the ratio of short-term debt/Total debt.

\subsection{Independent variables}

The independent variables refer to the factors that affect firm's debt policy. The authors have covered a wide range of factors of capital structure that were examined in the literature empirically. The independent variables are summarized in Table 1. The summary statistics of the independent variables are presented in Table 2. 


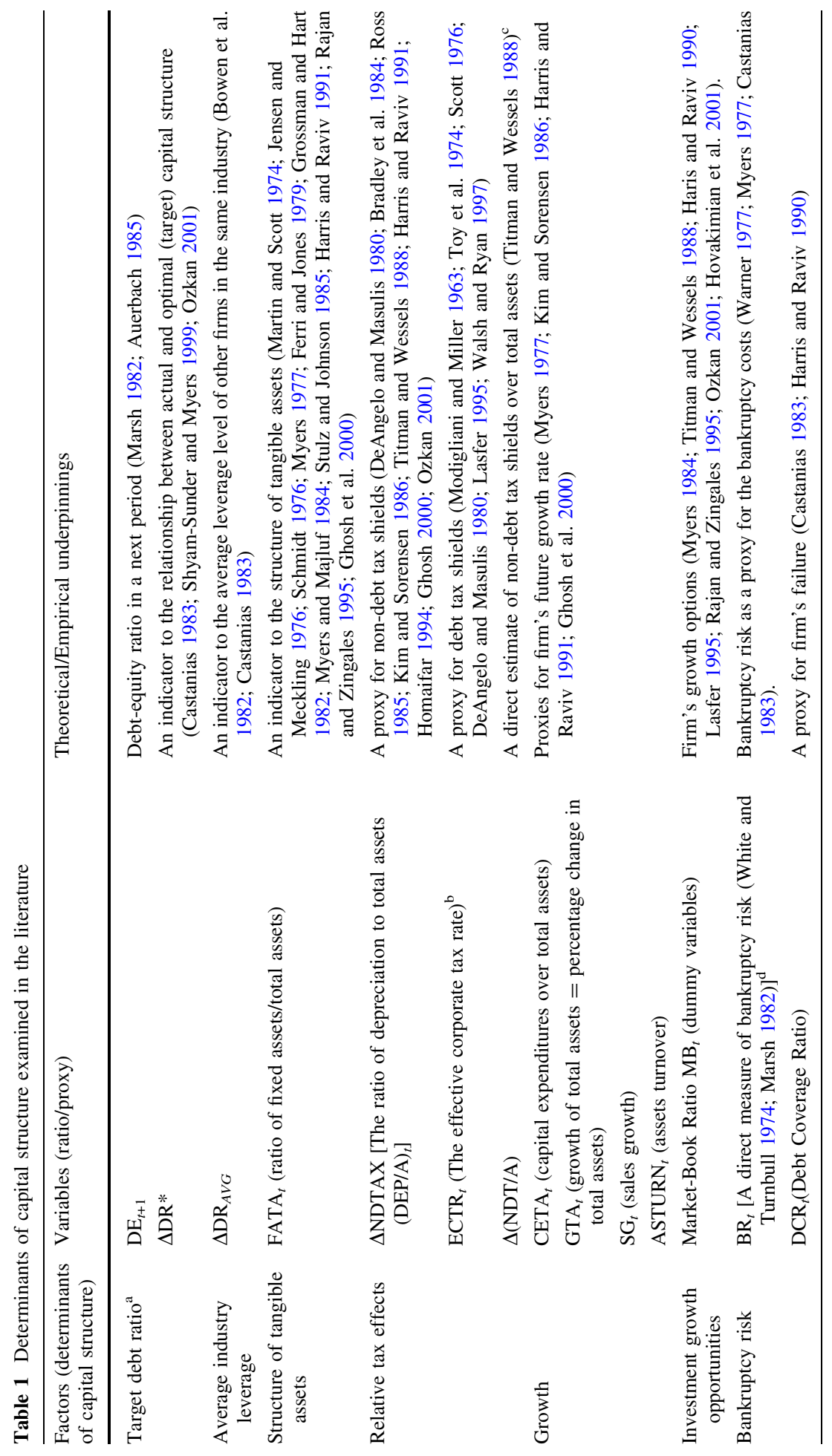




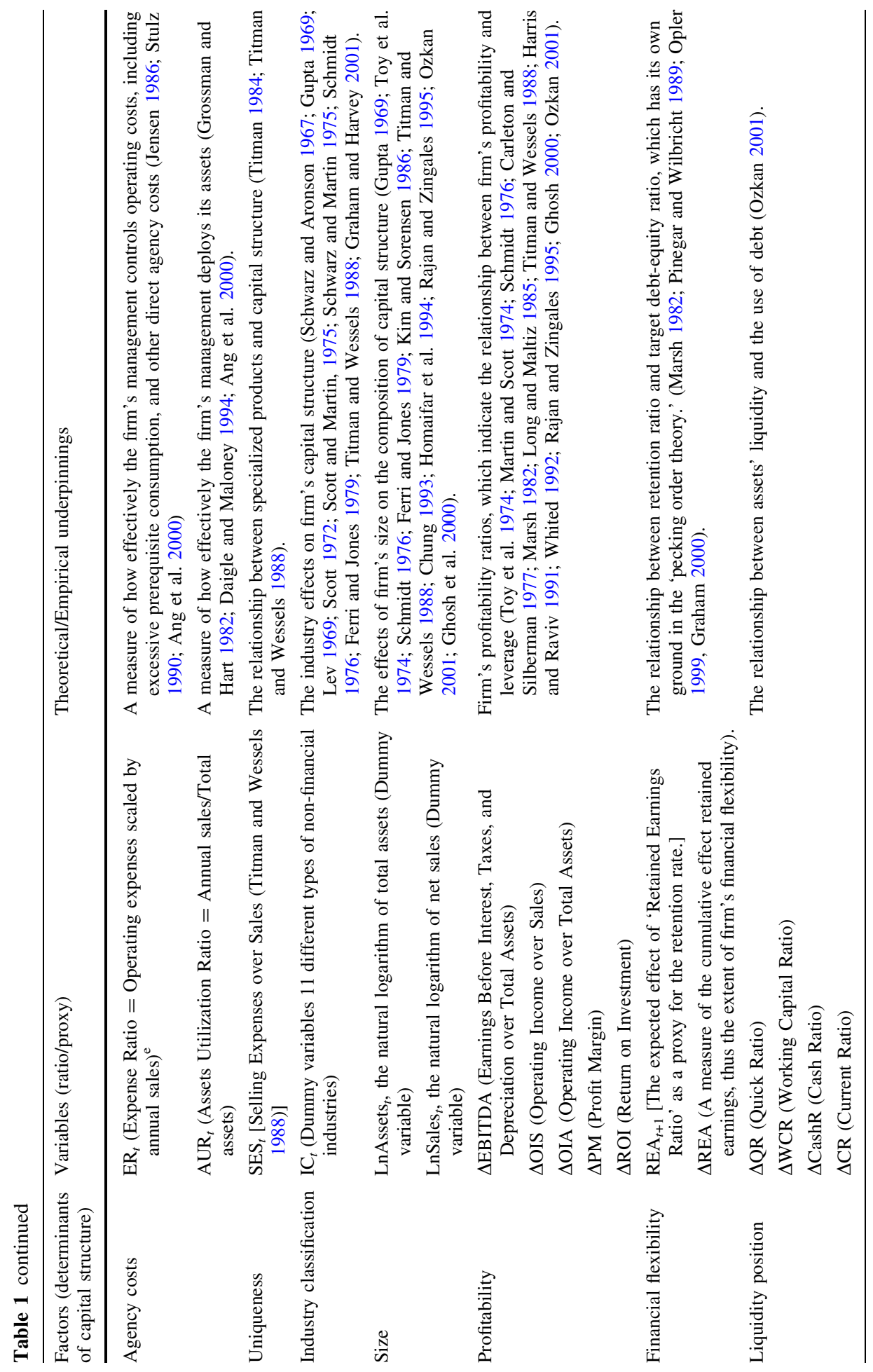




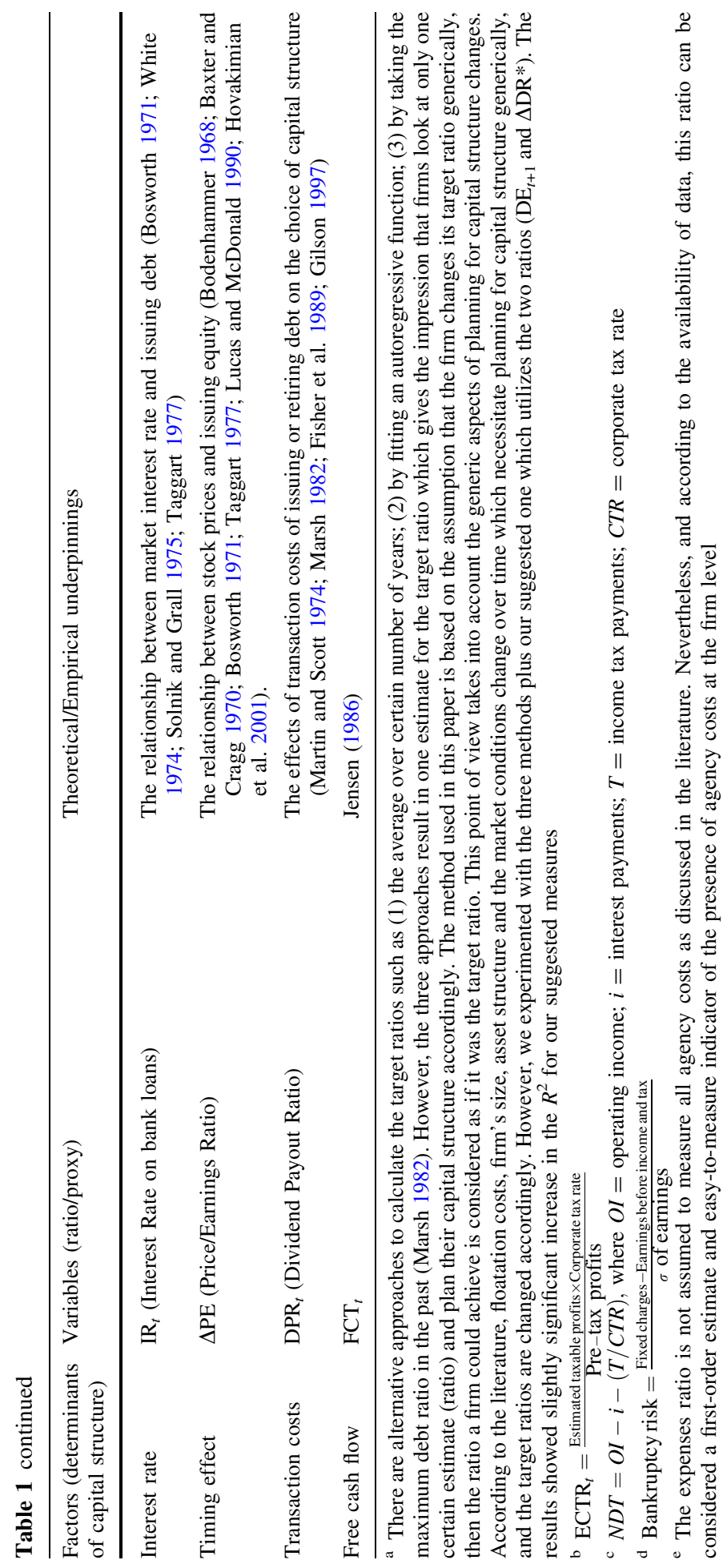


Table 2 Summary statistics of variables used for modeling the capital structure decision

\begin{tabular}{|c|c|c|c|c|c|c|}
\hline Variables & Ratio/Proxy & Mean & SD & Min & Median & $\operatorname{Max}$ \\
\hline Long-term debt ratio & $\Delta \mathrm{LTDR}_{t}$ & -0.01 & 0.154 & -2 & 0 & 1.358 \\
\hline Short-term debt ratio & $\Delta \mathrm{STDR}_{t}$ & -0.02 & 0.427 & -5.54 & -0.1 & 3.165 \\
\hline Target debt ratio & $\mathrm{DE}_{t+1}$ & -0.01 & 0.38 & -6.13 & 0.001 & 4.5 \\
\hline Average industry leverage & $\Delta \mathrm{ADR}_{A V G}$ & -0.01 & 0.14 & -0.54 & -0.01 & 0.48 \\
\hline Structure of tangible assets & FATA $_{t}$ & 0.24 & 0.3 & 0.002 & 0.18 & 5.33 \\
\hline Relative tax effects & $\Delta$ NDTAX $_{t}$ & -0.02 & 0.23 & -4.3 & 0 & 0.24 \\
\hline Growth & $\mathrm{GTA}_{t}$ & 0.22 & 1.13 & -0.9 & 0.05 & 15.05 \\
\hline \multirow{3}{*}{$\begin{array}{l}\text { Investment growth } \\
\text { opportunities } \\
\text { (MB ratio) }\end{array}$} & High MB & 0.05 & 0.22 & 0 & 0 & 1 \\
\hline & Average MB & 0.29 & 0.45 & 0 & 0 & 1 \\
\hline & Low MB & 0.65 & 0.47 & 0 & 1 & 1 \\
\hline Bankruptcy risk & $\mathrm{DCR}_{t}$ & 76.9 & 11.4 & -8.8 & 3.01 & 25.3 \\
\hline Agency costs & $\mathrm{ER}_{t}$ & 0.15 & 0.17 & -0.01 & 0.11 & 1.8 \\
\hline \multirow[t]{11}{*}{ Industry classification (IC) ${ }^{\mathrm{a}}$} & $\mathrm{IC} 1$ & 0.03 & 0.17 & 0 & 0 & 1 \\
\hline & IC2 & 0.01 & 0.10 & 0 & 0 & 1 \\
\hline & IC3 & 0.09 & 0.29 & 0 & 0 & 1 \\
\hline & IC4 & 0.08 & 0.28 & 0 & 0 & 1 \\
\hline & IC5 & 0.06 & 0.24 & 0 & 0 & 1 \\
\hline & IC6 & 0.06 & 0.24 & 0 & 0 & 1 \\
\hline & IC7 & 0.07 & 0.26 & 0 & 0 & 1 \\
\hline & IC8 & 0.13 & 0.33 & 0 & 0 & 1 \\
\hline & IC9 & 0.22 & 0.41 & 0 & 0 & 1 \\
\hline & IC10 & 0.07 & 0.26 & 0 & 0 & 1 \\
\hline & IC11 & 0.10 & 0.31 & 0 & 0 & 1 \\
\hline \multirow[t]{3}{*}{ Size $\left(\operatorname{Ln}\right.$ Assets $\left._{t}\right)$} & Large size & 0.3 & 0.46 & 0 & 0 & 1 \\
\hline & Medium size & 0.35 & 0.48 & 0 & 0 & 1 \\
\hline & Small size & 0.34 & 0.47 & 0 & 0 & 1 \\
\hline Profitability & $\Delta \mathrm{EBITDA}_{t}$ & -0.03 & 0.8 & -12.2 & -0.01 & 12.3 \\
\hline Financial flexibility & $\mathrm{REA}_{t+1}$ & 0.21 & 0.24 & 0 & 0.16 & 4.1 \\
\hline Liquidity position & $\Delta \operatorname{CashR}_{t}$ & -0.31 & 6.2 & -13.8 & -0.001 & 1.9 \\
\hline Interest rate & $\mathrm{IR}_{t}$ & 0.14 & 0.01 & 0.13 & 0.14 & 0.16 \\
\hline Timing effect & $\Delta \mathrm{PE}_{t}$ & 6.86 & 10.8 & -41.5 & 0.02 & 20.6 \\
\hline Transaction costs & $\mathrm{DPR}_{t}$ & 0.94 & 11.3 & 0 & 0.35 & 25.1 \\
\hline
\end{tabular}

The two dependent variables are changes in long-term debt ratio $\left(\Delta \mathrm{LTDR}_{t}\right)$ and changes in the short-term debt ratio $\left(\Delta \mathrm{STDR}_{t}\right)$. The other variables are the independents. The data covers the years from 1998 to 2004. The sample consists of 99 non-financial firms

${ }^{\text {a }}$ ICs are dummies for the industry type. IC1 = Agriculture \& Fisheries; IC2 = Gas, Oil \& Mining; IC3 = Food \& Beverages; IC4 = Mills \& Storages; IC5 = Textiles, Garments \& Consumers Goods; IC6 = Paper, Packaging \& Plastics; IC7 = Chemicals \& Fertilizers; IC8 = Pharmaceuticals \& Health Care; IC9 = Building Materials, Cement \& Contracting; IC10 = Engineering Industries \& Electrical Equipments; IC11 = Housing \& Real Estate 


\section{Data and methodology}

\subsection{Data}

The data are obtained from many sources. The data related to firms' income statement and balance sheet are obtained from the firms' annual reports, stock market authorities and Kompass Egypt Financial Year Book (Fiani \& Partners). The interest rate data is published by the IMF: International Financial Statistics. The data cover seven years 1998-2004. The total number of firms included in the study is 99 firms. The sample firms were selected according to two criteria. First, the non-financial firms amongst the 100 actively trading firms in Egypt stock market. Second, those non-financial firms amongst the 100 firms with the highest market value.

\subsection{Methodology}

The methodology in this paper aims at selecting the most important factors that affect firms' long-term debt ratio and short-term debt ratio. The authors employ ten model selection criteria to choose the best subset predictors of the capital structure decisions. Then, the subset which is selected by the maximum number of criteria is chosen to be the identified subset, e.g., the model that shows the group of factors (predictors) that affects the actual financing (capital structure) decision.

\section{The statistical modeling approach: the subset selection criteria}

Over the last three decades, several subset selection criteria have been proposed and studied in the linear regression models. These criteria have two basic elements. The first element is a function of error variance estimator which measures the goodness of fit. The second is a function of the number of unknown parameters which penalizes overfitting. In general, most selection criteria minimize the quantity:

$$
\text { Criteria }=n \log \left(R S S_{m}\right)+d_{m} F
$$

where $n$ is the sample size, $R S S_{m}$ is the minimum least squares' residual sum of squares for the model with $m$ predictors which is equal to

$$
R S S_{m}=\left(y-X_{m} \hat{\beta}_{m}\right)^{T}\left(y-X_{m} \hat{\beta}_{m}\right)
$$

where $\hat{\beta}$ is the minimum least squares estimates of the model parameters. The constant $d_{m}$ is the number of parameters $m$ in the model. The constant $F$ represents the penalty imposed to the $R S S_{m}$ for each additional parameter used in the model. It is worth noting that different penalty constants result in different selection criteria.

\subsection{The adjusted coefficient of determination $\left(R_{\mathrm{a}}^{2}\right)$}

The adjusted coefficient of determination $R_{\mathrm{a}}^{2}$ is defined as follows:

$$
R_{a}^{2}=1-\left(\frac{n-1}{n-p}\right) \frac{R S S}{T S S}
$$


where $p$ is the number of parameters and TSS is the total sum of squares which is equal toTSS $=\sum\left(y_{t}-\bar{y}\right)^{2}, \bar{y}$ is the sample mean. The adjusted coefficient of determination may decrease when adding a variable to the model since the reduction in RSS may be more than offset by the loss of a degree of freedom in the denominator $n-p$. Therefore, the model with the highest $R_{\mathrm{a}}^{2}$ is identified as the best model.

\subsection{Mallows' criterion $\left(C_{p}\right)$}

Mallows (1973) defines the $C_{p}$ statistic as:

$$
C_{p}=\frac{R S S_{m}}{S^{2}}-(n-2 m)
$$

where $S^{2}$ is the estimate for the residual variance given by $S^{2}=R S S_{p} / n-p$ and $p$ is the total number of predictors. The $C_{p}$ criterion identifies the subset of predictors with the smallest $C_{p}$ value (Mallows 1973; Miller 1990).

\subsection{Akaike's information criterion (AIC)}

The Akaike's information criterion (AIC) is proposed by Akaike (1973) as a statistic incorporating Kullback-Leibler information with the use of maximum likelihood principles and negative entropy. The AIC is one of the most popular criteria for model selection. It is defined as:

$$
A I C=n \log \left(R S S_{m}\right)+2 d_{m}
$$

It is clear that the AIC is a special case of (1) when $F=2$. The AIC identifies the subset with the smallest AIC value. The AIC tends to overestimate the dimension of the model (Akaike 1973; Miller 1990).

\subsection{Bayes information criterion (BIC)}

Schwarz (1978) proposed the Bayes information criterion (BIC) as a Bayesian solution to the model selection problem. The BIC was derived as a large sample approximation of Bayes factor using the posterior-probability criterion and evaluating the leading terms of its asymptotic expansion. Schwarz assumed a fixed penalty for guessing the wrong model and considered an infinite sequence of nested models each of which has a non-zero prior probability. The BIC is a special case of (1) when $F=\log (n)$, that is:

$$
B I C=n \log \left(R S S_{m}\right)+\log (n) d_{m}
$$

The BIC identifies the subset with the minimum value. When the number of observations is large, BIC penalizes additional parameters much more than AIC, leading to more parsimonious models. In large samples, BIC is equivalent to a Bayesian procedure that selects the model with the highest posterior (Schwarz 1978; Miller 1990).

\subsection{Final prediction error (FPE)}

Akaike (1969) proposed the FPE to select the best subset by choosing the model that minimizes a form of prediction mean squared error. This criterion is defined as: 


$$
F P E=\left(1+\frac{2 d_{m}}{n}\right) S^{2}
$$

where $S^{2}$ is the estimate for the residual variance given by $S^{2}=R S S_{p} / n-p$ and $p$ is the total number of predictors. According to Akaike's theory, in a collection of different models, the chosen model is the one with the smallest FPE.

\subsection{Hannan and Quinn criterion (HQ)}

Following a similar approach to Akaike (1969, 1973), Hannan and Quinn (1979) suggested a penalty term as $\log \log n$. Hannan and Quinn's criterion (HQ) is defined as:

$$
H Q=n \log \left(R S S_{m}\right)+\log \log n d_{m}
$$

HQ criterion is consistent, in a sense that it ensures that the actual model will be selected with probability unity as the sample size increases. HQ is a special case of (1) when $F=\log \log n$.

\subsection{Smith and Spiegelhalter criterion (SSC)}

Smith and Spiegelhalter (1980) employed Bayesian approach for model selection. They showed an approximate correspondence between Bayes factors and criterion (1) when $F=1.5$. The SSC is defined as:

$$
S S C=n \log \left(R S S_{m}\right)+1.5 d_{m}
$$

\subsection{Shibata criterion (SC)}

Shibata (1980) investigated the asymptotic efficiency of AIC and showed that, when the true model has infinite dimension, AIC is efficient as the sample size approaches infinity. Shibata's criterion (SC) is defined as:

$$
S C=n \log \left(R S S_{m}\right)+n \log \left(n+2 d_{m}\right)
$$

It is worth noting that $S C$ is a special case of (1) when $F=n\left(\log \left(n+2 d_{m}\right) / d\right)$. The SC identifies the subset with the smallest $S C$ value (Shibata 1980; Miller 1990).

\subsection{Risk inflation criterion (RIC)}

George and Foster (1994) proposed the Risk Inflation Criterion (RIC) which minimizes

$$
R I C=n \log \left(R S S_{m}\right)+2 p \log \left(d_{m}\right)
$$

The RIC asymptotically minimizes the maximum predictive risk inflation when the predictors are orthogonal. In addition, the $R I C$ is conservative since it is related to the expected size of the largest $t$-statistic when all predictors are orthogonal and their coefficients are zeros (George and Foster 1994; Foster and George 2000; Miller 1990). 


\subsection{Bias-variance criterion (BIVAR)}

Young (1982) suggested the Bias-Variance BIVAR Criterion as a weighted mean of Mallows' criteria $C_{p}$ and the number of parameters $d_{m}$. The BIVAR is defined as:

$$
B I V A R=w C_{p}+(1-w) d_{m}
$$

where $w$ is a constant weight. In this study we set $w=0.5$.

\section{Results}

It is worth noting that the ten criteria are monotone functions of the residual sum of squares $R S S$ for subsets with the same number of predictors. That is, the best subset is the one that minimizes $R S S$ for each size $r$, where $r=1,2, \ldots, P-1$. Nevertheless, the direct search for the subsets with minimum $R S S$ by visiting all possible subsets is impractical since the number of candidate subsets increases exponentially with the number of predictors. In fact, in our case where 28 predictors are considered, the direct search for best subsets takes 22 days!, using a Pentium 4, 2400 MH PC.

Other authors such as Furnival and Wilson (1974) and Hocking (1976) have developed elegant procedures which reduce the amount of computations required for examining a subset and avoid examining all possible subsets. The Minitab package reports the subsets with the maximum $R^{2}$ (or equivalently with minimum $R S S$ ) for each number of predictors. Then, a Matlab macro is written by the authors to compute the other criteria (which are not reported by Minitab) where RSS is used as an input in the Matlab macro.

\subsection{How does the subset selection work?}

This section shows the empirical results of the statistical modeling of the determinants of long-term debt and short-term debt. This section is organized as follows. First, according to the statistical modeling process, it describes how the subset selection is done. The results of the statistical modeling of long-term and short-term debt ratios are presented in Tables 3 and 4. Second, this section shows the results of the potential use of short-term debt to minimize underinvestment costs which are presented in Table 5 and the results of the potential overlap between short-term and long-term debt are presented in (6).

Table 3 shows the subset of predictors that influence the long-term debt financing. In Table 3, each column represents the selected model by one criterion while each row represents the status of the corresponding predictor selected by each criterion. When a predictor is included in the selected model by one criterion, a check mark $\sqrt{ }$ is put in the intersection cell of the predictor's row and the criterion's column.

In search for the candidate group (subset) of determinants of long-term debt financing, two approaches are developed. The first approach is to search for the criteria that include the same number of variables. Table 3 shows that there are two candidate subsets of determinants of long-term debt financing. Each of the two subsets is selected by three criteria. The first subset is selected by $\mathrm{C}_{p}$, FPE and BIVAR criteria and it includes the variables $D E_{t+1}, F A T A_{t}, \Delta$ NDTAX $_{t}, G T A_{t}, \mathrm{MB} 1$ (high growth opportunities), $R E A_{t+1}$, and $I R_{t}$. The second subset is selected by AIC, HQ and SSC criteria and it includes the variables $D E_{t+1}, \Delta \mathrm{ADR}_{A V G}, F A T A_{t}, \Delta \mathrm{NDTAX}_{t}, G T A_{t}, \mathrm{MB} 1, R E A_{t+1}$, and $I R_{t}$. Note that the second subset has one additional determinant which is average industry leverage $\triangle \mathrm{ADR}_{A V G}$. 
Table 3 Best subsets for long-term debt financing

\begin{tabular}{|c|c|c|c|c|c|c|c|c|c|c|c|}
\hline \multirow[t]{2}{*}{ Variables } & \multicolumn{10}{|c|}{ Model selection criteria } & \multirow[t]{2}{*}{$n_{i}$} \\
\hline & $R_{a}^{2}$ & $\mathrm{CP}$ & AIC & BIC & FPE & HQ & SSC & $\mathrm{SC}$ & BIVAR & RIC & \\
\hline $\mathrm{DE}_{t+1}$ & $\sqrt{ }$ & $\sqrt{ }$ & $\sqrt{ }$ & & $\sqrt{ }$ & $\sqrt{ }$ & $\sqrt{ }$ & $\sqrt{ }$ & $\sqrt{ }$ & $\sqrt{ }$ & 9 \\
\hline$\Delta \mathrm{ADR}_{A V G}$ & $\sqrt{ }$ & & $\sqrt{ }$ & & & $\sqrt{ }$ & $\sqrt{ }$ & $\sqrt{ }$ & & $\sqrt{ }$ & 6 \\
\hline FATA $_{t}$ & $\sqrt{ }$ & $\sqrt{ }$ & $\sqrt{ }$ & $\sqrt{ }$ & $\sqrt{ }$ & $\sqrt{ }$ & $\sqrt{ }$ & $\sqrt{ }$ & $\sqrt{ }$ & $\sqrt{ }$ & 10 \\
\hline$\Delta$ NDTAX $_{t}$ & $\sqrt{ }$ & $\sqrt{ }$ & $\sqrt{ }$ & & $\sqrt{ }$ & $\sqrt{ }$ & $\sqrt{ }$ & $\sqrt{ }$ & $\sqrt{ }$ & $\sqrt{ }$ & 9 \\
\hline $\mathrm{GTA}_{t}$ & $\sqrt{ }$ & $\sqrt{ }$ & $\sqrt{ }$ & $\sqrt{ }$ & $\sqrt{ }$ & $\sqrt{ }$ & $\sqrt{ }$ & $\sqrt{ }$ & $\sqrt{ }$ & $\sqrt{ }$ & 10 \\
\hline MB1 & $\sqrt{ }$ & $\sqrt{ }$ & $\sqrt{ }$ & & $\sqrt{ }$ & $\sqrt{ }$ & $\sqrt{ }$ & $\sqrt{ }$ & $\sqrt{ }$ & $\sqrt{ }$ & 9 \\
\hline MB2 & & & & & & & & $\sqrt{ }$ & & $\sqrt{ }$ & 2 \\
\hline $\mathrm{DCR}_{t}$ & & & & & & & & $\sqrt{ }$ & & $\sqrt{ }$ & 2 \\
\hline $\mathrm{ER}_{t}$ & & & & & & & & $\sqrt{ }$ & & $\sqrt{ }$ & 2 \\
\hline $\mathrm{IC} 1$ & & & & & & & & $\sqrt{ }$ & & $\sqrt{ }$ & 2 \\
\hline IC2 & & & & & & & & $\sqrt{ }$ & & $\sqrt{ }$ & 2 \\
\hline IC3 & & & & & & & & $\sqrt{ }$ & & $\sqrt{ }$ & 2 \\
\hline IC4 & & & & & & & & $\sqrt{ }$ & & $\sqrt{ }$ & 2 \\
\hline IC5 & & & & & & & & $\sqrt{ }$ & & $\sqrt{ }$ & 2 \\
\hline IC6 & & & & & & & & $\sqrt{ }$ & & $\sqrt{ }$ & 2 \\
\hline IC7 & & & & & & & & $\sqrt{ }$ & & $\sqrt{ }$ & 2 \\
\hline IC8 & & & & & & & & $\sqrt{ }$ & & $\sqrt{ }$ & 2 \\
\hline IC9 & & & & & & & & $\sqrt{ }$ & & $\sqrt{ }$ & 2 \\
\hline IC10 & & & & & & & & $\sqrt{ }$ & & $\sqrt{ }$ & 2 \\
\hline IC11 & & & & & & & & $\sqrt{ }$ & & $\sqrt{ }$ & 2 \\
\hline $\begin{array}{l}\text { Large-size } \\
\text { firms }\end{array}$ & & & & & & & & $\sqrt{ }$ & & $\sqrt{ }$ & 2 \\
\hline $\begin{array}{l}\text { Medium- } \\
\quad \text { size } \\
\text { firms }\end{array}$ & & & & & & & & $\sqrt{ }$ & & $\sqrt{ }$ & 2 \\
\hline$\Delta$ EBITDA $_{t}$ & $\sqrt{ }$ & & & & & & & $\sqrt{ }$ & & $\sqrt{ }$ & 3 \\
\hline $\mathrm{REA}_{t+1}$ & $\sqrt{ }$ & $\sqrt{ }$ & $\sqrt{ }$ & & $\sqrt{ }$ & $\sqrt{ }$ & $\sqrt{ }$ & $\sqrt{ }$ & $\sqrt{ }$ & $\sqrt{ }$ & 9 \\
\hline$\Delta \operatorname{CashR}_{t}$ & & & & & & & & $\sqrt{ }$ & & $\sqrt{ }$ & 2 \\
\hline $\mathrm{IR}_{t}$ & $\sqrt{ }$ & $\sqrt{ }$ & $\sqrt{ }$ & & $\sqrt{ }$ & $\sqrt{ }$ & $\sqrt{ }$ & $\sqrt{ }$ & $\sqrt{ }$ & $\sqrt{ }$ & 9 \\
\hline$\Delta \mathrm{PE}_{t}$ & & & & & & & & $\sqrt{ }$ & & $\sqrt{ }$ & 2 \\
\hline $\mathrm{DPR}_{t}$ & & & & & & & & $\sqrt{ }$ & & $\sqrt{ }$ & 2 \\
\hline
\end{tabular}

The second approach for determining the candidate subset is to select the variables which are selected by the maximum number of criteria. This is the approach preferred and adopted by the authors. This can be done when the number of variables corresponding to the elements in the last column $n_{i}$ : is greater than or equal a certain number. When we choose the variables which are selected by 9 criteria or more we obtain the same determinants of the first subset and the second subset is obtained when we select the variables chosen by 6 or more criteria. Indeed, for this reason the second approach outperforms the first one, considering that the major objective is to select the group of predictors that conform to the maximum number of criteria. Accordingly, the first chosen subset represents the group of determinants that affect the long-term debt financing decision. 
Table 4 Best subsets for short-term debt financing

\begin{tabular}{|c|c|c|c|c|c|c|c|c|c|c|c|}
\hline \multirow[t]{2}{*}{ Variables } & \multicolumn{10}{|c|}{ Model selection criteria } & \multirow[t]{2}{*}{$n_{i}$} \\
\hline & $R_{a}^{2}$ & $\mathrm{CP}$ & AIC & BIC & FPE & HQ & SSC & SC & BIVAR & RIC & \\
\hline $\mathrm{DE}_{t+1}$ & $\sqrt{ }$ & $\sqrt{ }$ & $\sqrt{ }$ & & $\sqrt{ }$ & $\sqrt{ }$ & $\sqrt{ }$ & $\sqrt{ }$ & $\sqrt{ }$ & $\sqrt{ }$ & 9 \\
\hline$\Delta \mathrm{ADR}_{A V G}$ & & & & & & & & $\sqrt{ }$ & & $\sqrt{ }$ & 2 \\
\hline FATA $_{t}$ & $\sqrt{ }$ & $\sqrt{ }$ & $\sqrt{ }$ & $\sqrt{ }$ & $\sqrt{ }$ & $\sqrt{ }$ & $\sqrt{ }$ & $\sqrt{ }$ & $\sqrt{ }$ & $\sqrt{ }$ & 10 \\
\hline$\Delta$ NDTAX $_{t}$ & $\sqrt{ }$ & $\sqrt{ }$ & $\sqrt{ }$ & & $\sqrt{ }$ & $\sqrt{ }$ & $\sqrt{ }$ & $\sqrt{ }$ & $\sqrt{ }$ & $\sqrt{ }$ & 9 \\
\hline $\mathrm{GTA}_{t}$ & $\sqrt{ }$ & $\sqrt{ }$ & $\sqrt{ }$ & $\sqrt{ }$ & $\sqrt{ }$ & $\sqrt{ }$ & $\sqrt{ }$ & $\sqrt{ }$ & $\sqrt{ }$ & $\sqrt{ }$ & 10 \\
\hline MB1 & $\sqrt{ }$ & & & & & & & $\sqrt{ }$ & & $\sqrt{ }$ & 3 \\
\hline MB2 & & & & & & & & $\sqrt{ }$ & & $\sqrt{ }$ & 2 \\
\hline $\mathrm{DCR}_{t}$ & & & & & & & & $\sqrt{ }$ & & $\sqrt{ }$ & 2 \\
\hline $\mathrm{ER}_{t}$ & & & & & & & & $\sqrt{ }$ & & $\sqrt{ }$ & 2 \\
\hline IC1 & & & & & & & & $\sqrt{ }$ & & $\sqrt{ }$ & 2 \\
\hline IC2 & & & & & & & & $\sqrt{ }$ & & $\sqrt{ }$ & 2 \\
\hline IC3 & & & & & & & & $\sqrt{ }$ & & $\sqrt{ }$ & 2 \\
\hline IC4 & & & & & & & & $\sqrt{ }$ & & $\sqrt{ }$ & 2 \\
\hline IC5 & & & & & & & & $\sqrt{ }$ & & $\sqrt{ }$ & 2 \\
\hline IC6 & & & & & & & & $\sqrt{ }$ & & $\sqrt{ }$ & 2 \\
\hline IC7 & $\sqrt{ }$ & $\sqrt{ }$ & $\sqrt{ }$ & & $\sqrt{ }$ & $\sqrt{ }$ & $\sqrt{ }$ & $\sqrt{ }$ & & $\sqrt{ }$ & 8 \\
\hline IC8 & & & & & & & & $\sqrt{ }$ & & $\sqrt{ }$ & 2 \\
\hline IC9 & & & & & & & & $\sqrt{ }$ & & $\sqrt{ }$ & 2 \\
\hline IC10 & & & & & & & & $\sqrt{ }$ & & $\sqrt{ }$ & 2 \\
\hline IC11 & $\sqrt{ }$ & & & & & $\sqrt{ }$ & $\sqrt{ }$ & $\sqrt{ }$ & & $\sqrt{ }$ & 5 \\
\hline $\begin{array}{l}\text { Large-size } \\
\text { firms }\end{array}$ & & & & & & & & $\sqrt{ }$ & & $\sqrt{ }$ & 2 \\
\hline $\begin{array}{l}\text { Medium- } \\
\quad \text { size } \\
\text { firms }\end{array}$ & & & & & & & & $\sqrt{ }$ & & $\sqrt{ }$ & 2 \\
\hline$\Delta \mathrm{EBITDA}_{t}$ & $\sqrt{ }$ & $\sqrt{ }$ & $\sqrt{ }$ & & $\sqrt{ }$ & $\sqrt{ }$ & $\sqrt{ }$ & $\sqrt{ }$ & $\sqrt{ }$ & $\sqrt{ }$ & 9 \\
\hline $\mathrm{REA}_{t+1}$ & & & & & & & & $\sqrt{ }$ & & $\sqrt{ }$ & 2 \\
\hline$\Delta$ CashR $_{t}$ & & & & & & & & $\sqrt{ }$ & & $\sqrt{ }$ & 2 \\
\hline $\mathrm{IR}_{t}$ & $\sqrt{ }$ & $\sqrt{ }$ & $\sqrt{ }$ & & $\sqrt{ }$ & $\sqrt{ }$ & $\sqrt{ }$ & $\sqrt{ }$ & & $\sqrt{ }$ & 8 \\
\hline$\Delta \mathrm{PE}_{t}$ & & & & & & & & $\sqrt{ }$ & & $\sqrt{ }$ & 2 \\
\hline $\mathrm{DPR}_{t}$ & & & & & & & & $\sqrt{ }$ & & $\sqrt{ }$ & 2 \\
\hline
\end{tabular}

The same procedures and approach are used in the case of short-term debt financing, short-term debt/total debt and changes in total debt ratio. The results are shown in Tables 3-6. Scanning the elements of Table 4 indicates that the identified subset for shortterm debt financing is selected by $\mathrm{C}_{p}$, AIC and FPE criteria and it includes $D E_{t+1}, F A T A_{t}$, $\triangle N D T A X_{t}, G T A_{t}$, IC7, $\triangle E B I T D A_{t}$ and $I R_{t}$. The same identified subsets of predictors are obtained if we choose the predictors that appear in the selected models of 8 criteria or more. Therefore, this subset is chosen to represent the group of determinants that affect the shortterm debt financing decision. Similarly, the same procedures are employed to examine the potential overlaps between long-term and short-term debt financing. The results are shown in Table 5. In addition, the potential problem of using short-term debt to minimize the underinvestment problem is examined and the results are presented in Table 6. 
Table 5 Best subsets the ratio of short-term debt/total debt

\begin{tabular}{|c|c|c|c|c|c|c|c|c|c|c|c|}
\hline \multirow[t]{2}{*}{ Variables } & \multicolumn{10}{|c|}{ Model selection criteria } & \multirow[t]{2}{*}{$n_{i}$} \\
\hline & $R_{a}^{2}$ & $\mathrm{CP}$ & AIC & $\mathrm{BIC}$ & FPE & HQ & SSC & $\mathrm{SC}$ & BIVAR & RIC & \\
\hline $\mathrm{DE}_{t+1}$ & & & & & & & & $\sqrt{ }$ & & $\sqrt{ }$ & 2 \\
\hline$\Delta \mathrm{ADR}_{A V G}$ & & & & & & & & $\sqrt{ }$ & & $\sqrt{ }$ & 2 \\
\hline FATA $_{t}$ & $\sqrt{ }$ & $\sqrt{ }$ & $\sqrt{ }$ & $\sqrt{ }$ & $\sqrt{ }$ & $\sqrt{ }$ & $\sqrt{ }$ & $\sqrt{ }$ & $\sqrt{ }$ & $\sqrt{ }$ & 10 \\
\hline$\Delta$ NDTAX $_{t}$ & & & & & & & & $\sqrt{ }$ & & $\sqrt{ }$ & 2 \\
\hline $\mathrm{GTA}_{t}$ & & & & & & & & $\sqrt{ }$ & & $\sqrt{ }$ & 2 \\
\hline MB1 & $\sqrt{ }$ & $\sqrt{ }$ & $\sqrt{ }$ & & $\sqrt{ }$ & $\sqrt{ }$ & $\sqrt{ }$ & $\sqrt{ }$ & $\sqrt{ }$ & $\sqrt{ }$ & 9 \\
\hline MB2 & & & & $\sqrt{ }$ & & & & $\sqrt{ }$ & & $\sqrt{ }$ & 3 \\
\hline MB3 & $\sqrt{ }$ & $\sqrt{ }$ & $\sqrt{ }$ & & $\sqrt{ }$ & $\sqrt{ }$ & $\sqrt{ }$ & $\sqrt{ }$ & $\sqrt{ }$ & $\sqrt{ }$ & 9 \\
\hline $\mathrm{DCR}_{t}$ & $\sqrt{ }$ & & & & & & & $\sqrt{ }$ & & $\sqrt{ }$ & 3 \\
\hline $\mathrm{ER}_{t}$ & $\sqrt{ }$ & $\sqrt{ }$ & $\sqrt{ }$ & $\sqrt{ }$ & $\sqrt{ }$ & $\sqrt{ }$ & $\sqrt{ }$ & $\sqrt{ }$ & $\sqrt{ }$ & $\sqrt{ }$ & 10 \\
\hline IC1 & $\sqrt{ }$ & $\sqrt{ }$ & $\sqrt{ }$ & & & $\sqrt{ }$ & $\sqrt{ }$ & $\sqrt{ }$ & & $\sqrt{ }$ & 7 \\
\hline IC2 & $\sqrt{ }$ & $\sqrt{ }$ & $\sqrt{ }$ & & & $\sqrt{ }$ & $\sqrt{ }$ & $\sqrt{ }$ & & $\sqrt{ }$ & 7 \\
\hline IC3 & & & & & & & & $\sqrt{ }$ & & $\sqrt{ }$ & 2 \\
\hline IC4 & & & & & & & & $\sqrt{ }$ & & $\sqrt{ }$ & 2 \\
\hline IC5 & $\sqrt{ }$ & $\sqrt{ }$ & $\sqrt{ }$ & & $\sqrt{ }$ & $\sqrt{ }$ & $\sqrt{ }$ & $\sqrt{ }$ & $\sqrt{ }$ & $\sqrt{ }$ & 9 \\
\hline IC6 & & & & & & & & $\sqrt{ }$ & & $\sqrt{ }$ & 2 \\
\hline IC7 & $\sqrt{ }$ & & & & & & & $\sqrt{ }$ & & $\sqrt{ }$ & 3 \\
\hline IC 8 & & & & & & & & $\sqrt{ }$ & & $\sqrt{ }$ & 2 \\
\hline IC9 & $\sqrt{ }$ & $\sqrt{ }$ & $\sqrt{ }$ & $\sqrt{ }$ & $\sqrt{ }$ & $\sqrt{ }$ & $\sqrt{ }$ & $\sqrt{ }$ & $\sqrt{ }$ & $\sqrt{ }$ & 10 \\
\hline IC10 & $\sqrt{ }$ & $\sqrt{ }$ & $\sqrt{ }$ & & $\sqrt{ }$ & $\sqrt{ }$ & $\sqrt{ }$ & $\sqrt{ }$ & $\sqrt{ }$ & $\sqrt{ }$ & 9 \\
\hline IC11 & $\sqrt{ }$ & $\sqrt{ }$ & $\sqrt{ }$ & $\sqrt{ }$ & $\sqrt{ }$ & $\sqrt{ }$ & $\sqrt{ }$ & $\sqrt{ }$ & $\sqrt{ }$ & $\sqrt{ }$ & 10 \\
\hline $\begin{array}{l}\text { Large-size } \\
\text { firms }\end{array}$ & $\sqrt{ }$ & $\sqrt{ }$ & $\sqrt{ }$ & $\sqrt{ }$ & $\sqrt{ }$ & $\sqrt{ }$ & $\sqrt{ }$ & $\sqrt{ }$ & $\sqrt{ }$ & $\sqrt{ }$ & 10 \\
\hline $\begin{array}{l}\text { Medium- } \\
\text { size } \\
\text { firms }\end{array}$ & & & & & & & & $\sqrt{ }$ & & $\sqrt{ }$ & 2 \\
\hline$\Delta$ EBITDA $_{t}$ & & & & & & & & $\sqrt{ }$ & & $\sqrt{ }$ & 2 \\
\hline $\mathrm{REA}_{t+1}$ & $\sqrt{ }$ & $\sqrt{ }$ & $\sqrt{ }$ & & & $\sqrt{ }$ & $\sqrt{ }$ & $\sqrt{ }$ & & $\sqrt{ }$ & 7 \\
\hline$\Delta$ CashR $_{t}$ & $\sqrt{ }$ & & & & & & & $\sqrt{ }$ & & $\sqrt{ }$ & 3 \\
\hline $\mathrm{IR}_{t}$ & & & & & & & & $\sqrt{ }$ & & $\sqrt{ }$ & 2 \\
\hline$\Delta \mathrm{PE}_{t}$ & & & & & & & & $\sqrt{ }$ & & $\sqrt{ }$ & 2 \\
\hline $\mathrm{DPR}_{t}$ & $\sqrt{ }$ & & & & & & & $\sqrt{ }$ & & $\sqrt{ }$ & 3 \\
\hline
\end{tabular}

\section{Discussion}

The results reported in Tables 3-6 are summarized in Table 7. The latter shows the most common determinants of long-term debt and short-term debt chosen by the most criteria employed by the modeling process. When one determinant is chosen by many criteria, it means that the determinant is highly associated with the measure of capital structure, thus the determinant is quite relevant to explain debt financing decisions in Egypt.

Table 7 indicates many aspects of the practice of corporate debt financing decisions. First, five out of the seven ratios and/or proxies are considered common determinants of 
Table 6 Best subsets for the changes in all debt

\begin{tabular}{|c|c|c|c|c|c|c|c|c|c|c|c|}
\hline \multirow[t]{2}{*}{ Variables } & \multicolumn{10}{|c|}{ Model selection criteria } & \multirow[t]{2}{*}{$n_{i}$} \\
\hline & $R_{a}^{2}$ & $\mathrm{CP}$ & AIC & $\mathrm{BIC}$ & FPE & HQ & SSC & $\mathrm{SC}$ & BIVAR & RIC & \\
\hline $\mathrm{DE}_{t+1}$ & $\sqrt{ }$ & $\sqrt{ }$ & $\sqrt{ }$ & & $\sqrt{ }$ & $\sqrt{ }$ & $\sqrt{ }$ & $\sqrt{ }$ & $\sqrt{ }$ & $\sqrt{ }$ & 9 \\
\hline$\Delta \mathrm{ADR}_{A V G}$ & & & & & & & & $\sqrt{ }$ & & $\sqrt{ }$ & 2 \\
\hline FATA $_{t}$ & $\sqrt{ }$ & $\sqrt{ }$ & $\sqrt{ }$ & $\sqrt{ }$ & $\sqrt{ }$ & $\sqrt{ }$ & $\sqrt{ }$ & $\sqrt{ }$ & $\sqrt{ }$ & $\sqrt{ }$ & 10 \\
\hline$\Delta$ NDTAX $_{t}$ & $\sqrt{ }$ & & & & & & & $\sqrt{ }$ & & $\sqrt{ }$ & 3 \\
\hline $\mathrm{GTA}_{t}$ & $\sqrt{ }$ & $\sqrt{ }$ & $\sqrt{ }$ & $\sqrt{ }$ & $\sqrt{ }$ & $\sqrt{ }$ & $\sqrt{ }$ & $\sqrt{ }$ & $\sqrt{ }$ & $\sqrt{ }$ & 10 \\
\hline MB1 & $\sqrt{ }$ & $\sqrt{ }$ & $\sqrt{ }$ & & $\sqrt{ }$ & $\sqrt{ }$ & $\sqrt{ }$ & $\sqrt{ }$ & $\sqrt{ }$ & $\sqrt{ }$ & 9 \\
\hline MB2 & & & & & & & & $\sqrt{ }$ & & $\sqrt{ }$ & 2 \\
\hline MB3 & & & & & & & & $\sqrt{ }$ & & $\sqrt{ }$ & 2 \\
\hline $\mathrm{DCR}_{t}$ & & & & & & & & $\sqrt{ }$ & & $\sqrt{ }$ & 2 \\
\hline $\mathrm{ER}_{t}$ & & & & & & & & $\sqrt{ }$ & & $\sqrt{ }$ & 2 \\
\hline $\mathrm{IC} 1$ & & & & & & & & $\sqrt{ }$ & & $\sqrt{ }$ & 2 \\
\hline IC2 & & & & & & & & $\sqrt{ }$ & & $\sqrt{ }$ & 2 \\
\hline IC3 & & & & & & & & $\sqrt{ }$ & & $\sqrt{ }$ & 2 \\
\hline $\mathrm{IC} 4$ & & & & & & & & $\sqrt{ }$ & & $\sqrt{ }$ & 2 \\
\hline IC5 & & & & & & & & $\sqrt{ }$ & & $\sqrt{ }$ & 2 \\
\hline IC6 & & & & & & & & $\sqrt{ }$ & & $\sqrt{ }$ & 2 \\
\hline IC7 & $\sqrt{ }$ & $\sqrt{ }$ & $\sqrt{ }$ & & & $\sqrt{ }$ & $\sqrt{ }$ & $\sqrt{ }$ & & $\sqrt{ }$ & 7 \\
\hline IC8 & & & & & & & & $\sqrt{ }$ & & $\sqrt{ }$ & 2 \\
\hline IC9 & & & & & & & & $\sqrt{ }$ & & $\sqrt{ }$ & 2 \\
\hline IC10 & & & & & & & & $\sqrt{ }$ & & $\sqrt{ }$ & 3 \\
\hline IC11 & & & & & & & & $\sqrt{ }$ & & $\sqrt{ }$ & 3 \\
\hline $\begin{array}{l}\text { Large-size } \\
\text { firms }\end{array}$ & & & & & & & & $\sqrt{ }$ & & $\sqrt{ }$ & 2 \\
\hline $\begin{array}{l}\text { Medium- } \\
\text { size } \\
\text { firms }\end{array}$ & & & & & & & & $\sqrt{ }$ & & $\sqrt{ }$ & 2 \\
\hline$\Delta$ EBITDA $_{t}$ & $\sqrt{ }$ & $\sqrt{ }$ & $\sqrt{ }$ & & $\sqrt{ }$ & $\sqrt{ }$ & $\sqrt{ }$ & $\sqrt{ }$ & $\sqrt{ }$ & $\sqrt{ }$ & 9 \\
\hline $\mathrm{REA}_{t+1}$ & & & & & & & & $\sqrt{ }$ & & $\sqrt{ }$ & 2 \\
\hline$\Delta \operatorname{CashR}_{t}$ & & & & & & & & $\sqrt{ }$ & & $\sqrt{ }$ & 2 \\
\hline $\mathrm{IR}_{t}$ & $\sqrt{ }$ & & & & & & & $\sqrt{ }$ & & $\sqrt{ }$ & 3 \\
\hline$\Delta \mathrm{PE}_{t}$ & & & & & & & & $\sqrt{ }$ & & $\sqrt{ }$ & 2 \\
\hline $\mathrm{DPR}_{t}$ & & & & & & & & $\sqrt{ }$ & & $\sqrt{ }$ & 2 \\
\hline
\end{tabular}

both long-term debt and short-term debt. These common determinants are equity/debt ratio, fixed assets/total assets, non-debt tax shields, growth of total assets, and interest rates. The robustness of this result is considered when the same predictors are examined with regard to another alternative dependent variable, which is the change in total debt ratio. The latter shows that three predictors (equity/debt ratio, fixed assets/total assets and growth of total assets) out of the five common predictors are also determinants of the change in total debt ratio. This result indicates a considerable resemblance between long-term and short-term debts when making capital structure decisions. That is, short-term debt is renewable and used on long-term basis as a source of long-term debt financing. This supports the debt financing scenario mentioned earlier in the description of the dependent 


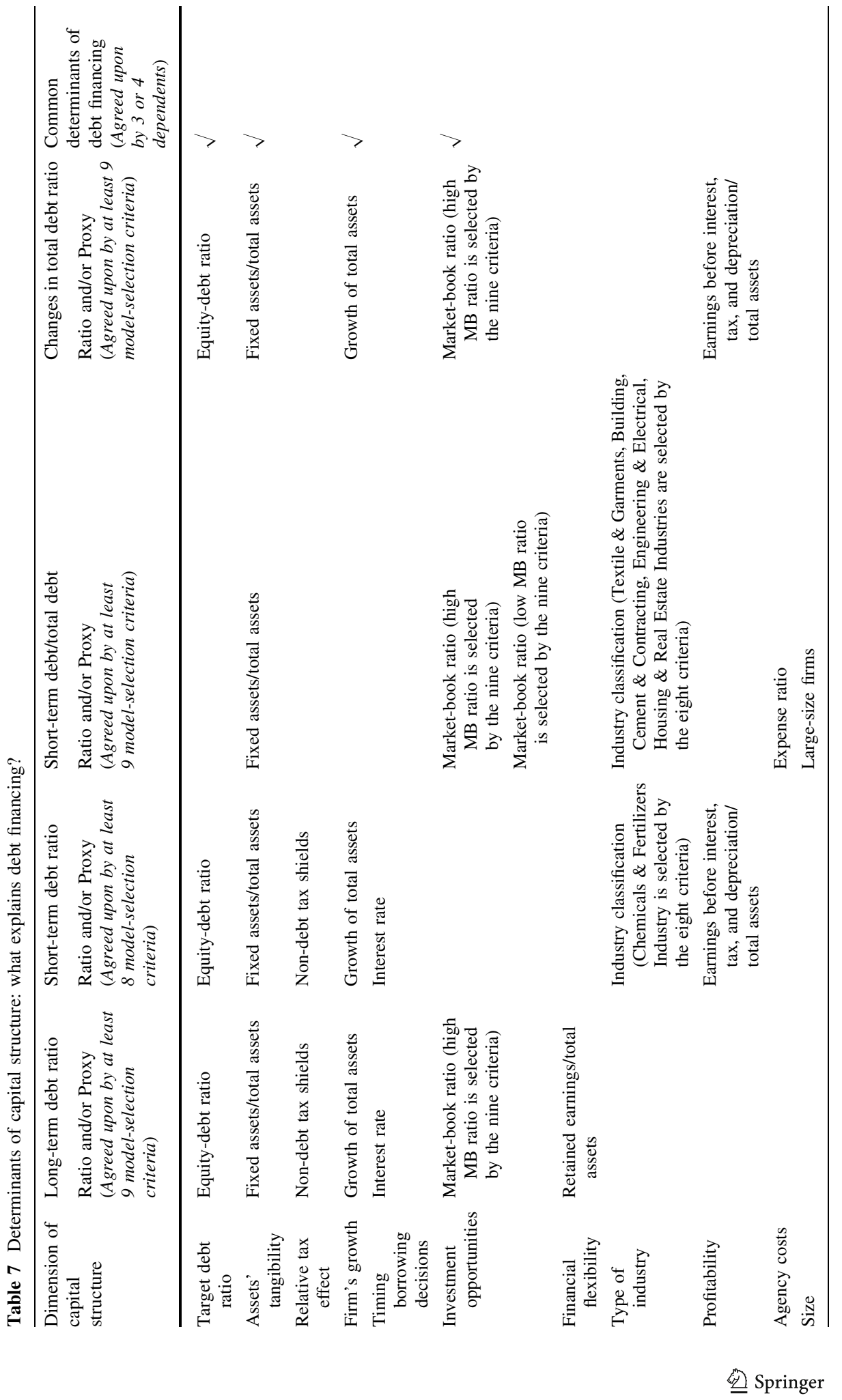


variables and also comparable to the results of Spanish firms reported by Sánchez-Vidal and Martin-Ugendo (2005).

Second, as for the long-term debt financing, the availability of good investment opportunities in the market is one of the causes to change firm's debt financing. In this case, firms use both long-term debt and retained earnings to finance the available investment opportunities. Table 7 also shows an important aspect of the short-term debt financing. That is, the availability of good investment opportunities (being proxied by high MB ratio) supports Myers (1977) and Graham (1996) theory that firms may use short-term debt financing to minimize underinvestment costs. As for the industry type, the results show that short-term debt financing is considerably important to certain industries which are the Chemicals \& Fertilizers, textile \& garments, building \& contracting, engineering and housing \& real estate. In general, industry effects have been studied by Schwarz and Aronson (1967), Gupta (1969), Lev (1969), Scott (1972), Schmidt (1976), Scott and Martin (1975) and Ferri and Jones (1979). They all found significant industry effects on debt ratios. Titman (1984) raised the magnitude of this relationship through studying the liquidation decision where the results indicate that firms that make special products will find liquidation costly. Titman and Wessels (1988) report a negative relationship between debt ratios and the dummy variables that control for and refer to the firms that produce specialized products (such as machines and equipments). Contrary to Titman's (1984) prediction, Graham and Harvey (2001) find that high-tech firms, which are assumed to produce specialized products, are less likely than other firms to limit debt for not giving their customers and suppliers an impression that the firm may go out of business. The results also show that firm's profitability is not to be considered an exclusive determinant of short-term debt financing decisions since it is a also a determinant to changes in total debt ratio. This does not render profitability a robust determinant of short-term debt financing.

Third, Table 7 shows important implications regarding the practice of theories of capital structure. As Myers (2001) points out, the practice of corporate financing decisions could be dominated by the combined effects of the three theories. The contribution of the subset selection approach is to examine the dominant determinants (variables) influencing the practice of debt financing decisions. The results show that in both cases of long-term debt financing and short-term debt financing, the trade-off theory dominates relatively. The trade-off theory assumes that the firm will borrow to a level that balances the tax advantages and possible financial distress. Therefore, firm's tax advantage (tax shield) plays the dominant role in this theory.

The results show that, in the case of long-term and short-term debt financing, the effects of 'target debt ratio' (using debt/equity ratio) and 'tax shields' (using non-debt tax shields) reflect the robust effects of the 'trade-off theory.' The literature provides evidence on the trade-off-related determinants of corporate debt financing. Modigliani and Miller (1963) and Scott (1976) show the effects of corporate tax rate on firm's debt policy. DeAngelo and Masulis (1980) argue that there is a positive relationship in which firms subject to lower corporation tax rates will employ less debt in their capital structure. Lasfer (1995) reports the same positive relationship in the long-run, but no significant effect in the short-run. Walsh and Ryan (1997) found that tax considerations are significant in determining debt and equity decisions of the UK firms. In Toy et al.'s (1974) study, they found that executives regarded tax as a very important debt ratio determinant. The other survey conducted by Graham and Harvey (2001) reports that tax advantage is of moderate importance for medium-size firms, and of high importance for large, regulated dividend-paying firms (e.g., firms that have high corporate tax rates and, therefore, large tax incentives to use debt). 
Table 7 also shows the role of other determinants of capital structure. The first determinant is the 'assets tangibility' being measured by the proxy ratio of fixed assets to total assets. In this study, this determinant has robust effects on both firms' long-term and shortterm debt financing. In this regard, this result is comparable to Tsai's (2005) result that the optimal capital structure tends to involve debt financing for firms with more value in tangible assets. The literature on the theories of capital structure assumes that tangible assets are easy to collateralize and thus they reduce the agency costs of debt (Myers and Majluf 1984; Stulz and Johnson 1985; Harris and Raviv 1991; Rajan and Zingales 1995). The literature provides some different results on the relationship between debt and fixed assets. On one hand, Toy et al. (1974) show that corporate executives considered liquidity of assets a highly determinant of debt ratio. Schmidt (1976) and Ferri and Jones (1979) found a negative correlation between total debt and the proportion of fixed assets. On the other hand, the works of Galai and Masulis (1976), Jensen and Meckling (1976) and Myers (1977) provide evidence on positive relationships between firm's debt ratios and their collateralized assets. The existence of uncollaterable assets leads a firm to change its capital structure favoring equity financing rather than debt financing. Grossman and Hart (1982) argue that higher collateralized debt levels prevent managers from over consuming firm's perquisites. Myers and Majluf (1984) and Myers (1984) indicate that when managers have better information than outside investors, the former find it advantageous to issue secured debt. In this regard, the information managers have about their firms' assets can positively affect assets collaterlability if this information helps creditors exercising an effective monitoring role. Titman and Wessels (1988) find an effect of assets' collateral value on firm's capital structure choice. Martin and Scott (1974) and Ghosh et al. (2000) find the ratio of fixed assets to total assets a positive and significant determinant of firm's capital structure.

The next determinant that affects both long-term and short-term debt financing is firm's growth being proxied in this study by growth of total assets. The agency theory argues on the existence of a negative relationship between firm's expected future growth and long-term debt levels. As the agency theory states, equity-controlled firms have a tendency to invest suboptimally to expropriate wealth from bondholders and the cost associated with this agency relationship is likely to be higher for growing firms. This negative relationship has been reached by Kim and Sorensen (1986), Harris and Raviv (1991) and Ghosh et al. (2000). Nevertheless, Gupta (1969) and Toy et al. (1974) found that total debt ratios were positively related to growth measured by sales growth and asset turnover. Graham and Harvey's survey (2001) shows that many growth firms claim that customers might not purchase their products if they are worried that debt usage might cause the firm to go out of business. This is consistent with Titman's theory (1984) if growth firms produce unique products.

Although, the results in Table 7 show that market interest rate is a common determinant of both long-term and short-term debt financing, the effect of interest rates disappeared with regard to change in total debt ratio. This does not render interest rate a robust determinant of debt financing.

The results show that the long-term debt financing is also affected by the existence of much investment growth opportunities being proxied by the MB ratio. Table 7 shows that the high MB ratio is chosen as a determinant of long-term debt financing. The literature includes number of works that relate changes in firm's capital structure to the available growth options, hence investment opportunities. The latter are affected by the presence of long-term debt, which can cause an agency conflict between bondholders and shareholders (Myers 1977). That is, shareholders may underinvest if they perceive that the income will be used to pay off existing debt holders. This indicates a negative relationship between firm's debt and growth opportunities. Barclay et al. (1995) indicate that the most important 
systematic determinant of a company's capital structure and dividend yield would appear to be the extent of its investment opportunities. Myers (1977) and Graham (1996) argue that firms may limit total debt, or use short-term debt to minimize underinvestment costs. This is quite obvious in Table 7 since the high MB ratio is a determinant of changes in total debt ratio as well. This result comes in contrast to the results of other studies that debt usage is inversely related to growth options. Myers (1984), Williamson (1988) and Harris and Raviv (1990) argue on the relationship between growth opportunities, bankruptcy costs and financial leverage. They argue that the expected bankruptcy costs are higher for firms with greater growth opportunities. This leads to the conclusion that larger expected bankruptcy costs would in turn imply lower financial leverage. Titman and Wessels (1988) present additional evidence in which they argue that firms in growing industries incur higher agency costs since they have more flexibility in taking future investments. Lasfer (1995) provides evidence on the inverse relationship that firms with fewer growth opportunities have more debt in their capital structure. Rajan and Zingales (1995) found a negative correlation between market-to-book ratio and leverage driven by firms with high market-to-book ratios rather than by firms with low market-to-book ratios. This indicates that it is unlikely that financial distress (high leverage), which is associated with firms with low market-to-book ratios, is responsible for the negative correlation as suggested by Fama and French (1992). Lucas and McDonald (1990), Loughran and Ritter (1995), Rajan and Zingales (1995) and Hovakimian et al. (2001) present another reason for the market-to-book ratio to be negatively correlated with book leverage that stems from the tendency for firms to issue stocks when their stocks price is high relative to earnings or book value. Ozkan (2001) presented further evidence on the negative and statistically significant relationship between growth opportunities and leverage. According to his explanation, this negative relationship may give support to the prediction that firms, which have a relatively large proportion of intangible assets can not support a high leverage ratio. Nevertheless, Ozkan found a positive and statistically significant relationship between the lagged growth and leverage. He argues that the positive effect may happen because growth has a transitory effect on leverage ratios.

It is quite interesting to note that the results reported in Table 7 show considerable similarities and convergence with Booth et al.'s study (2001) of the determinants of capital structure in other ten developing countries but Egypt was not included in the sample countries. In the case of Egypt, Eldomiaty and Ismail (2004, 2005) and Eldomiaty (2004) have reached similar results about sample of Egyptian firms using the Bayesian methodology which stands on very different assumptions from the assumptions of the subset selection procedure employed in the present study. The converging and matchable results of those studies, therefore, add to the contribution of this paper since the methodology used in this study is quite different from the ones used in the other related studies mentioned earlier. This also shows a significant element of external validity of the results reported in this study as well as the other related studies. In addition, the matching results of this study and other related studies provide another support to what Booth et al. (2001) have concluded that the theory of capital structure is 'portable.' That is, corporate financing decisions in developing markets are influenced relatively by many determinants of capital structure that have evolved in developed markets.

\section{Conclusion}

The literature on the theories of capital structure has provided wide range of factors that can be used to describe the practice of corporate financing strategies. This paper is the first 
attempt to employ the methodology of model selection for determining the relevant determinants of debt financing decisions in transition markets in general and in Egypt in particular. The methodology used in this paper presents evidence that two models of corporate debt financing (long-term and short-term debt financing) show a robust influence of the trade-off theory. The final results can be considered as a first-order analysis to further examine the conditions under which firms' financing decisions and strategies are made and moving from one theory to another. The contribution of the paper is that the reported results converge relatively and considerably to the results of other related studies in developing markets, which is considered an element of external validity. This is true since the methodologies employed in the other related studies differ from the one used in the present study. The results have also empirical considerations since they show the relevant determinants of capital structure to the Egyptian capital market. These determinants are recommended to the practitioners when making debt financing decisions.

Open Access This article is distributed under the terms of the Creative Commons Attribution Noncommercial License which permits any noncommercial use, distribution, and reproduction in any medium, provided the original author(s) and source are credited.

\section{References}

Akaike H (1969) Fitting autoregressive models for control. Ann Math Stat 21:243:247

Akaike H (1973) Information theory and an extension of the maximum principle. In: Proceedings of the $2 \mathrm{nd}$ international symposium on information theory. Akademia Kiado, Budapest, pp 267-281

Ang, JS, Cole RA, Lin JW (2000) Agency costs and ownership structure. J Finan 55:81-106

Auerbach AJ (1985) Real determinants of corporate leverage. In: Friedman BM (ed) Corporate capital structure in the United States. University of Chicago Press, Chicago, pp 301-322

Baxter, ND, Cragg JG (1970) Corporate choice among long-term financing instruments. Rev Econ Stat 52:225-235

Bodenhammer L (1968) The effect of the size of public offerings of common stocks upon pre-offering stock prices. Unpublished Ph.D. dissertation, Harvard Business School

Booth L, Aivazian V, Demirguc-Kunt A, Maksimovic V (2001) Capital structure in developing countries. J Finan 56:87-130

Bosworth B (1971) Patterns of corporate external financing. Brookings Papers on Economic Activity 2:253279

Bowen RM, Daley LA, Huber CC (1982) Evidence on the existence and determinants of inter-industry differences of leverage. Finan Manag 11:10-20

Barclay MJ, Smith CW, Watts RL (1995) The determinants of corporate leverage and dividend policies. J Appl Corp Finan 7(5):4-19

Bradley M, Jarrell A, Han Kim E (1984) On the existence of an optimal capital structure: theory and evidence. J Finan 39:857-880

Carleton WT, Silberman IH (1977) Joint determination of rate of return and capital structure: an econometric analysis. J Finan 32:811-821

Castanias R (1983) Bankruptcy risk and optimal capital structure. J Finan 38:1617-1635

Chen AH, Han Kim E (1979) Theories of corporate debt policy: a synthesis. J Finan 34:371-384

Chung KH (1993) Asset characteristics and corporate debt policy: an empirical test. J Bus Finan Acc 20:83-98

Daigle KH, Maloney MT (1994) Residual claims in bankruptcy: an agency theory explanation. J Law Econ 37(1):157-192

DeAngelo H, Masulis R (1980) Optimal capital structure under corporate and personal taxation. J Finan Econ 8:3-29

Draper N, Smith H (1981) Applied regression analysis. New York, John Wiley

Eldomiaty TI (2004) Dynamics of financial signaling theory and systematic risk classes in transitional economy: perspectives from Egypt. J Finan Manag Anal 17(2):41-59

Eldomiaty TI, Ismail MA (2004) Bayesian identification of the predictors for capital structure in Egypt. Adv Appl Stat 4(2):193-212 
Eldomiaty TI, Ismail MA (2005) A Bayesian approach for testing the debt signaling hypothesis in a transitional market: perspectives from Egypt. Adv Quant Anal Finan Acc 4:163-194

Fama EF, French KR (1992) The cross-section of expected stock returns. J Finan 47:427-465

Ferri M, Jones W (1979) Determinants of financial structure: a new methodological approach. J Finan 34:631-644

Fiani and Partners. Kompass Egypt. Financial Year Book (Cairo: Fiani and Partners)

Fischer EO, Heinkel R, Zechner J (1989) Dynamic capital structure choice: theory and tests. J Finan 44:19-40

Frank MZ, Goyal VK (2004) Capital structure decisions: which factors are reliably important? http://papers.ssrn.com-sol3-papers.cfmabstract-id=567650

Foster D, George E (1994) The risk inflation criterion for multiple regression. Ann Stat 22(4):1947-1975

Furnival GM, Wilson RW (1974) Regression by leaps and bounds. Technometrics 16:499-511

Galai D, Masulis R (1976) The option pricing model and the risk factor of stock. J Finan Econ 3:53-81

George E, Foster D (2000) Calibration and empirical Bayes variable selection. Biometrika 87:731-747

Ghosh A, Cai F, Li W (2000) The determinants of capital structure. Am Bus Rev 18:129-132

Gilson SC (1997) Transaction costs and capital structure choice: evidence from financially distress firms. J Finan 52:111-133

Graham JR (1996) Debt and the marginal tax rate. J Finan Econ 41:41-73

Graham JR (2000) How big are the tax benefits of debt? J Finan 55:1901-1941

Graham JR, Harvey CR (2001) The theory and practice of corporate finance: evidence from the field. J Finan Econ 60:187-243

Grossman S, Hart O (1982) Corporate financial structure and managerial incentives. In: McCall J (ed) The economics of information and uncertainty. University of Chicago Press, Chicago

Gupta MC (1969) The effect of size, growth and industry on the financial structure of manufacturing companies. J Finan 24:517-529

Hannan EJ, Quinn BG (1979) The determination of the order of an autoregression. J R Stat Soc B 41:190-195

Harris M, Raviv A (1990) Capital structure and the informational role of debt. J Finan 45:321-349

Harris M, Raviv A (1991) The theory of capital structure. J Finan 46:297-355

Hocking RR (1976) The analysis and selection of variables in linear regression. Biometrics 32:1-52

Homaifar G, Zietz J, Benkato O (1994) An empirical model of capital structure: some new evidence. J Bus Finan Acc 21:1-14

Hovakimian A, Opler TC, Titman S (2001) Debt-equity choice. J Finan Quant Anal 36:1-24

Jensen MC (1986) Agency costs of free cash flow, corporate finance, and takeovers. Am Econ Rev 76:323-329

Jensen MC, Meckling WH (1976) Theory of the firm: managerial behavior, agency costs and ownership structure. J Finan Econ 3:305-360

Kim WS, Sorensen EH (1986) Evidence on the impact of the agency costs of debt on corporate debt policy. J Finan Quant Anal 21:131-144

Lasfer MA (1995) Agency costs, taxes and debt. Eur Finan Manag 1:265-285

Lev B (1969) Industry average as targets for financial ratios. J Acc Res 7:290-299

Long M, Maltiz I (1985) The investment financing nexus: some empirical evidence. Midland Corp Finan J 3:53-59

Loughran T, Ritter JR (1995) The new issues puzzle. J Finan 50:23-52

Lucas DJ, McDonald RL (1990) Equity issues and stock price dynamics. J Finan 45:1019-1043

Mallows CL (1973) Some comments on $C_{p}$. Technometrics 15:661-676

Marsh P (1982) The choice between equity and debt: an empirical study. J Finan 37:121-144

Martin JD, Scott DF Jr (1974) A discriminant analysis of the corporate debt-equity decision. Finan Manag 3:71-79

Miller MH (1988) The Modigliani-Miller proposition after thirty years. J Econ Perspect 2:99-120

Miller AJ (1990) Subset selection in regression. Chapman and Hall, London

Modigliani F, Miller MH (1963) Corporate income taxes and the cost of capital: a correction. Am Econ Rev 53:433-443

Myers SC (1977) Determinants of corporate borrowing. J Finan Econ 5:147-175

Myers SC (1984) The capital structure puzzle. J Finan 39:575-592

Myers SC, Majluf NS (1984) Corporate financing and investment decisions when firms have information that investors do not have. J Finan Econ 13:187-221

Myers SC (2001) Capital structure. J Econ Perspect 15:81-102

Opler T, Pinkowitz L, Stulz R, Williamson R (1999) The determinants and implications of corporate cash holdings. J Finan Econ 52:3-46

Ozkan A (2001) Determinants of capital structure and adjustment to long-run target: evidence from UK company panel data. J Bus Finan Acc 28:175-198 
Pinegar JM, Wilbricht L (1989) What managers think of capital structure theory: a survey. Finan Manag 18:82-91

Rajan RG, Zingales L (1995) What do we know about capital structure? Some evidence from international data. J Finan 50:1421-1460

Ross SA (1985) Debt and taxes and uncertainty. J Finan 40:637-657

Sánchez-Vidal J, Martin-Ugedo J (2005) Financing preferences of Spanish firms: evidence on the pecking order theory. Rev Quant Finan Acc 25(4):341-355

Schwarz G (1978) Estimating a dimension of a model. Ann Stat. 6:461-436

Schwarz G, Martin JD (1975) Industry influence on financial structure. Finan Manag 4:67-73

Schmidt RH (1976) Determinants of corporate debt ratios in Germany. European finance association proceedings. North Holland, Amsterdam

Schwarz E, Aronson JR (1967) Some surrogate evidence in support of the concept of optimal capital structure. J Finan 22:10-18

Scott DF Jr (1972) Evidence on the importance of financial structure. Finan Manag 1:45-50

Scott DF Jr, Martin JD (1975) Industry influence on financial structure. Finan Manag 4:67-73

Scott JH Jr (1976) A theory of optimal capital structure. Bell J Econ 7:33-54

Shibata R (1980) Asymptotically efficient selection of the order of the model for estimating parameters of a linear process. Ann Stat 8:147-164

Shyam-Sunder L, Myerst SC (1999) Testing static tradeoff against pecking order models of capital structure. J Finan Econ 51:219-244

Smith AFM, Spiegelhalter DJ (1980) Bayes factor and choice criteria for the linear models. J R Stat Soc B 42:213-220

Solnik BH, Grall J (1974/1975) Eurobonds: determining the demand for capital and the international interest rate structure. J Bank Res 5:218-230

Stulz RM, Johnson H (1985) An analysis of secured debt. J Finan Econ 14:501-521

Stulz RM, Johnson H (1990) Managerial discretion and optimal financing policies. J Finan Econ 26:3-28

Taggart RA Jr (1977) A model of corporate financing decisions. J Finan 32:1467-1484

Titman S (1984) The effect of capital structure on a firm's liquidation decision. J Finan Econ 13:137-151

Titman S, Wessels R (1988) The determinants of capital structure choice. J Finan 43:1-19

Toy N, Stonehill A, Remmers L, Wright R, Beekhuisen T (1974) A comparative international study of growth, profitability, and risk as determinants of corporate debt ratios in the manufacturing sector. J Finan Quant Anal 9:875-886

Tsai S-C (2005) Dynamic models of investment distortions. Rev Quant Finan Acc 25(4):357-381

Walsh EJ, Ryan J (1997) Agency and tax explanations of security issuance decisions. J Bus Finan Acc 24:943-961

Warner JB (1977) Bankruptcy costs: some evidence. J Finan 32(2):337-348

White WL (1974) Debt management and the form of business financing. J Finan 29:565-577

Whited T (1992) Debt, liquidity constraints, and corporate investment: evidence from panel data. J Finan $47: 1425-1460$

Williamson OE (1988) Corporate finance and corporate governance. J Finan 43:567-591

Young AS (1982) The Bivar criterion for selecting regressors. Technometrics 24:151-156 